\section{ALGUNAS NOTAS SOBRE REHABILITACION Y NUEVAS CONSTRUCCIONES EN VIEJOS SOPORTES}

\author{
Salvador Pérez Arroyo, \\ Catedrático de Construcción de la E.T.S. \\ de Arquitectura de Madrid
}

$105-1$

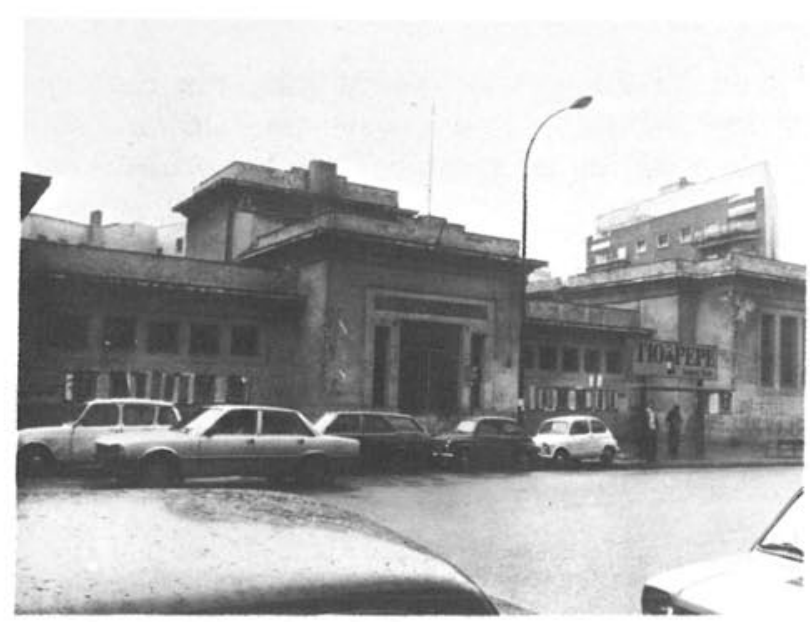

Ejemplo de restauración de una antigua casa de baños municipal para su conversión en casa de cultura, con una gran biblioteca y salón de actos.

\section{INTRODUCCION}

De nuevo es empresa atractiva el intervenir sobre construcciones y centros consolidados.

La Arquitectura comparte hoy sus espacios de información con los estudios históricos y las técnicas de restauración; toda una nube de términos y conceptos han sido desenterrados como almas de otro tiempo y vagan por revistas y libros en una apasionante y a veces confusa vuelta a nuestra historia.

Las ciudades viejas de Europa han dejado de exhibir con orgullo la clásica imagen del nuevo edificio de oficinas implantado en algún casco histórico. La obsesión de delimitar recintos y ela- borar catálogos absorbe a los ayuntamientos europeos que hasta ahora no lo habian hecho.

Las ya viejas reglas de especulación se han resentido y abarcan nuevos métodos, nuevas normas del juego con las que sea posible intervenir.

Los clásicos modelos de ciudades de los años 60 y 70 son aborrecidos por gran parte de la sociedad que sólo por necesidad aceptaría ocupar allí una plaza.

Es claro que se ha dejado de confiar en las nuevas construcciones hijas en tipo y modo del movimiento moderno. Le Corbusier aparece hoy de nuevo como un salvaje a los ojos de los jóvenes conservadores y sus grandes construcciones se van cargando de un aire siniestro y demoledor.

Las preocupaciones higienistas de Gropius nos recuerdan en la era de los antibióticos, más un grotesco sistema de estabulación que factores a tener en cuenta.

Las preocupaciones por los índices de iluminación propios de principios de siglo, o los complicados sistemas de acondicionamiento, sólo viven en razón de los intereses económicos de los viejos especuladores o de las casas que fabrican estos aparatos.

Del siglo en efecto se ha cogido lo bueno y abandonado las imágenes de utopia tecnológica.

La vivienda y la moda de plástico de los años 50 es un objeto Kitsch que se sirve en las imágenes de las portadas de disco de los B.52 o en los diseños de Fiorucci cargadas de una feroz ironía. Nada hay más atractivo que aquellas fotos, estas imágenes o estas modas en el marco de una ciudad o una vivienda antiguas.

La energia se sabe cara, pero nunca como hoy se ha aprendido a conocer dónde están los límites reales del confort.

La ciudad de clima regulado de un Fuller es también un sistema de aniquilación de la felicidad, en la que habria que explicar a los niños el sentido de las cuatro estaciones.

No quiero unirme a los que ya han denunciado como P. Blake el hundimiento de la visión funcio- 


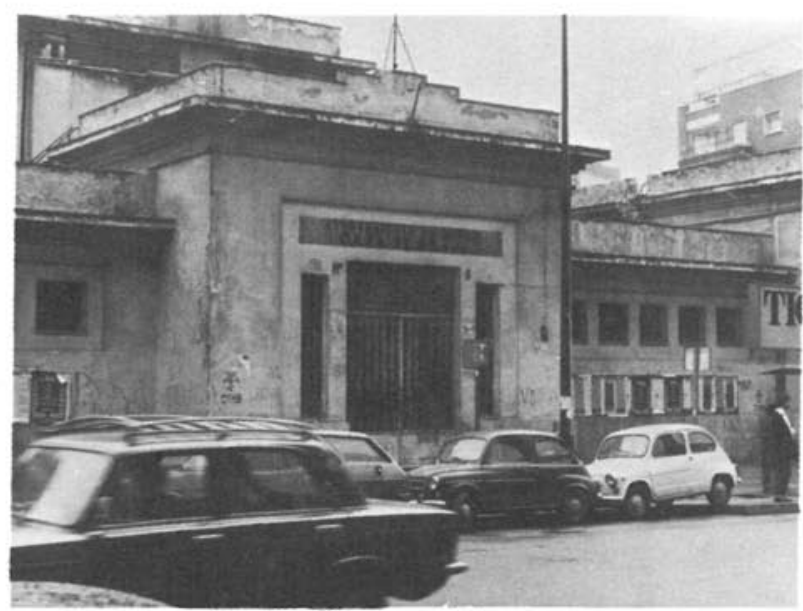

Las patologías constructivas en este-edificio se derivan del uso continuado del mismo, con un alto nivel de humedad interior, junto a un deficiente planteamiento constructivo. Los petos de fachada realizados con mortero de cal han producido una disgregación total de la fábrica.

nalista de la arquitectura. Desgraciadamente no ha sido únicamente la comprensión de este fracaso lo que ha llevado al interés por las viejas contrucciones y centros. Junto a las ya conocidas exigencias sociales, parecen haberse unido desajustes económicos de importancia que no se pueden analizar aquí, pero que han deteriorado las espectativas de beneficios, en razón de la inversión necesaria en nuevas construcciones en areas externas y de la capacidad adquisitiva de los futuros usuarios.

La primera respuesta frente a este problema fue simplemente volver al centro y destruirlo. Experiencias posteriores a la Segunda Guerra Mundial habian permitido la realización de grandes operaciones como la realizada en Stuttgart, ciudad casi arrasada por los bombardeos.

Importantes características de escala hacen sin embargo diferentes estas intervenciones de las que seguirian en años posteriores.

En cualquier caso se materializó como un aspecto diferenciador en muchas de ellas la existencia de trazados primitivos, edificios salvados de las ruinas o la simple necesidad de recuperar una imagen de centro histórico más próxima a la anterior que a los modernos barrios residenciales. Por ello, si se siguen las intervenciones en ciudades nuevas realizadas en paises como Suecia, se aprecia a su vez un deterioro progresivo de aquellos centros construidos en los años cincuenta frente a los posteriores. La diferencia entre Vallingby y el Orminge prefabricado, es en este caso simplemente la que media entre el abandono de las corrientes organicistas y la progresiva materialización de la arquitectura racional como un feroz medio de especulación.
Las tendencias de terciarización de los centros son también conocidas. Hoy han vuelto a cambiar estas ideas por lo menos en las ciudades desarrolladas.

La necesidad de remodelación ha permitido la implantación de centros residenciales de alto nivel que son lógicamente opuestos a la terciarización pura. Los términos del conflicto van, hacia quien debe y puede apropiarse de los centros y si es lícito destruir sus imágenes históricas. Hablaremos de ello más adelante, recordemos aquí tan sólo que la lucha se plantea en términos de apropiación de servicios, medios y espacios de privilegio que ya existen o son fáciles de restituir.

Las grandes remodelaciones, que implican destrucción de los soportes originales, se están abandonando, defendiéndose en estos momentos de crisis energética es decir económica, la simple puesta en uso de los viejos soportes.

A ello contribuyen las normativas, los catálogos ya mencionados, y la resistencia, siempre débil frente a las fuertes presiones, de los usuarios.

Desde un punto de vista económico puede ser más rentable para un país esta última solución en cuanto que no genera transferencias de sobre-beneficios en manos de la especulación y no se dilapida el patrimonio existente. Destruir un edificio puede significar construir dos veces, para el nuevo usuario y para el antiguo, trasladado a otro lugar.

Es conocido de todos, y en nuestro pais especialmente, el papel "singular" que ha representado la industria de la construcción y su enorme capacidad de desequilibrio económico en un momento de crisis energética.

Por razones económicas, sociales y culturales se ha vuelto a los centros y también a la conservación cada vez más exigente de edificios de interés.

Congresos, libros y revistas se dedican con profusión al tema. Se habla de conservar, restaurar, rehabilitar, etc. y se plantean los mayores y lógicos problemas. Nuevos usos, viejos usos, qué tipo de intervención es válido y qué pasa con las nuevas construcciones.

Este último punto se presenta como de un enorme interés. Si las legislaciones constructivas de los años 20 y 30 pretendian servir a criterios higienistas, las actuales sobre centros históricos y 
Informes de la Construcción/338

patrimonio están dirigidas a frenar la destrucción. Si aquéllas consiguieron un objetivo, pero perjudicaron de un modo directo a otros factores no estrictamente funcionales, con las actuales normativas de conservación puede ocurrir lo mismo. Hay que preguntarse por ello qué será de nuestras ciudades en el futuro, si serán simples decorados para turistas, o centros vivos y generadores de atracción, en los que tenga un lugar la buena arquitectura; todo ello habrá que definirlo.

Primero los conceptos de intervención, después, los medios y las técnicas. Los conceptos a través de una discusión más profunda sobre criterios. Los medios refiriéndonos en este caso a las posibles ayudas financieras y legales orquestadas por los poderes centrales y locales. Las técnicas, mencionando cómo se deben enfocar estos problemas desde un punto de vista constructivo.

Antes de pasar al primer punto no querría dejar de mencionar mi posición sobre la polarización en la ciudad. Con frecuencia en los coloquios y opiniones sobre estos temas se alude a la necesidad de eliminar la oposición entre centro y periferia; quien defiende esto no parece entender el sentido del desequilibrio que es parte de la misma historia de la ciudad y de la vida de los centros. No se pueden mezclar los problemas de necesidad o de equipamiento básico, que son siempre resolubles por medios económicos, con la necesidad de mantener ciudades con diferentes gradientes, en las que la aproximación al centro se presenta desde áreas más tranquilas y alejadas como una fuente de infinitas sensaciones, en las que el anonimato y el consumo o la simple presencia de espectáculos cumplen un papel catártico insustituible.

Si algún día esto no existe es porque no existen ciudades y éstas se han convertido en una malla indiferenciada de bloques soleados y ventilados en los que los clásicos problemas sicológicos ya descritos en el trabajo de "Piperek y Foramitti" (1) aparecerán en mayor escala.

Hay que pensar de nuevo en estos temas puesto que la revisión del concepto de centralidad, el redescubrimiento de antiguos modos de vida, etc. ponen en cuestión muchos de los objetivos asumidos por el movimiento moderno e influyen sobre los criterios de intervención en nuestras viejas ciudades.

\section{SOBRE LOS DISTINTOS CONCEPTOS}

Me refería antes a la enorme profusión de términos utilizados. Es preciso matizar de partida nues-

(1) "Anxieties of City Dwe/ers» en "the conservations of Cities» Unesco, 1975.

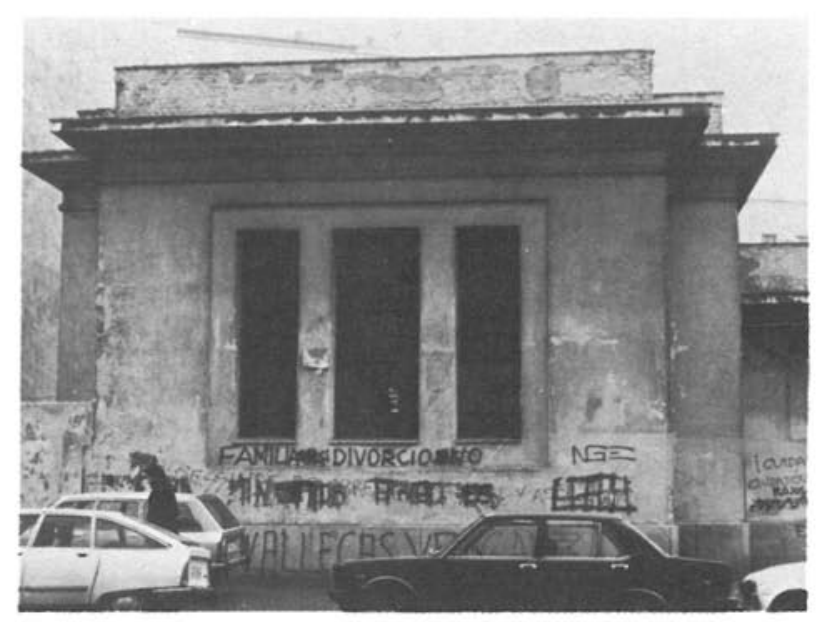

Las carpinterias metálicas han sufrido una fuerte oxidación que impide su cierre y apertura.

tro objetivo que no es hablar de restauración de edificios aislados de gran valor histórico artístico, sino de las intervenciones en viejos soportes y grandes áreas, para conseguir darles nueva vida.

El término rehabilitar, que podria también ser revitalizar, puede aproximarse a esto: es dar vida nue va a edificios muertos y con bajo rendimiento social. La remodelación afectaria a áreas de mayores dimensiones e incluso a barrios.

Se podria hablar de reconversiones, de estructuraciones $y$ otros términos; pienso sin embargo que nuestro objetivo queda delimitado entre la intervención aislada $y$, en un conjunto más amplio, con entidad propia.

En realidad es aceptada por todos la imposibilidad de conseguir resultados especiales sin actuar dentro de una politica general que favorezca la revitalización de estas áreas.

De igual modo es dificil en ocasiones la clasificación de un edificio como de valor histórico individual o ambiental.

A medida que nuestro interés por lo construido va ocupando periodos más próximos, el ámbito de protección se hace más amplio y edificios que hace años parecian excesivamente próximos en el tiempo, para ser objeto de protección, pasan a serlo una vez que se comprende su valor arquitectónico o simplemente histórico, o artesanal.

El valor historico es relativo con la cultura y la riqueza de cada pais o cada ciudad, sin olvidar que en muchas han existido mejores obras en los años treinta que en el XIX o XVIII, en función también de su historia específica. 


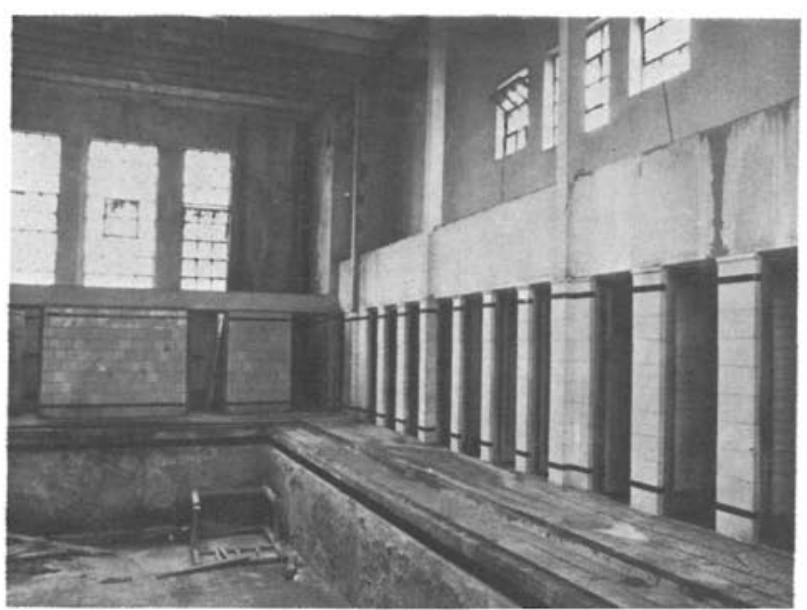

Vista interior de las piscinas en las que se acusan las humedades de cubierta y la excelente calidad del chapado cerámico en las cabinas.

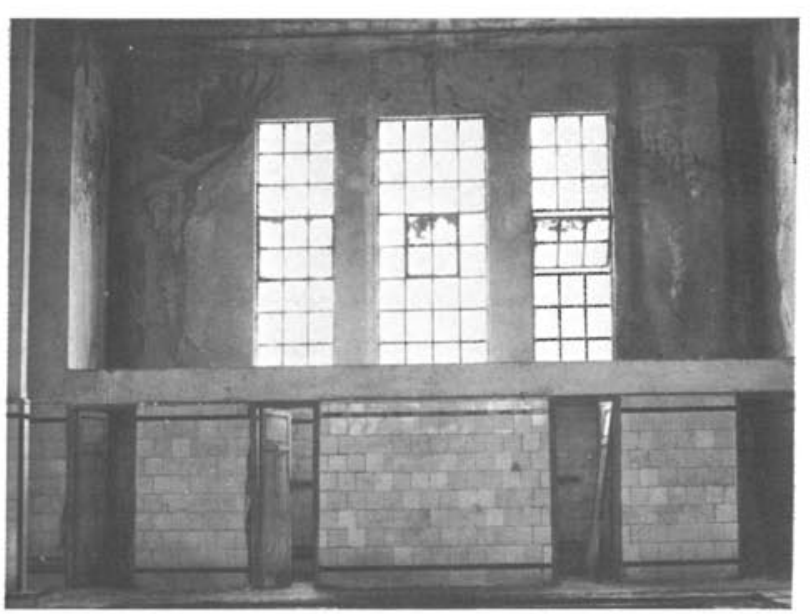

Destrucción de pinturas y enlucidos por bajantes obturadas.

Cuando escribo pienso en el New York del primer tercio de siglo o en la excelente arquitectura fascista italiana.

En España nos movemos entre problemas parecidos. Determinadas áreas madrileñas de los años cuarenta (posteriores a la guerra civil) son mejores que muchas del XIX e incluso del XVIII, sin embargo su proximidad ha permitido su destrucción.

La rehabilitación se presentará como un medio de volver a dar vida (no la misma) a centros o edificios fuera de uso. Se podrá conseguir manteniendo el programa anterior si es sólo un problema de obsolescencia técnica, instalaciones o mantenimiento, o cambiando el programa y el uso.

Son clásicos los ejemplos en todos los casos. Viejos mercados modernizados, edificios residenciales que se subdividen en más viviendas, o edificios de carácter público que pasan de mercados a museos o de iglesias a bibliotecas, etc.
En todos ellos nos tendremos que preguntar por los objetivos de la intervención y su posible inclusión en un programa de más largo alcance, y surgirán de inmediato distintos problemas sobre la licitud de variar los programas y los usos, o sobre la posibilidad de absorber en cada área el programa cultural previsto (1).

A estos mencionados se añaden los que se derivan de intervenir en áreas con una característica arquitectónica determinada. Una vez resueltos aquéllos aparece de nuevo uno de los mayores problemas hoy en debate, la necesidad de nuevas construcciones.

La sociedad industrial ha destruido en profundidad el sistema de vida de muchos de estos centros, en los que se plantean las intervenciones. Cuando se inician las políticas de rehabilitación no hay más que edificios fuera de uso a nivel técnico y unas poblaciones residuales cuyo equilibrio social dista de ser el que fue en su origen.

Asi pues se trata de sanear lo constructivo interviniendo en los usos y los programas estudiando aquello que es necesario al equilibrio social de carácter residual.

También existen con frecuencia solares vacios, e incluso edificios en los que técnicamente no es rentable conservar porque su valor no justificaria las construcciones necesarias; la politica de rehabilitación tenderá por tanto a intervenir con nuevas construcciones sin las que la zona, el barrio o la calle no adquiririan el nivel necesario para su definición como tal.

Las nuevas distribuciones interiores en el edificio, el saneamiento de fachadas, la restauración o la inclusión de nuevas construcciones por ocupación de solares o por ampliación de edificios existentes plantea de nuevo la misma problemática que se planteó desde el XIX en todas las doctrinas de restauración.

Para Ruskin intervenir era destruir, y el daño era mayor en razón de la vejez del edificio. "El verdadero sentido de la palabra restauración no lo comprende el público ni los que tienen el cuidado de velar por nuestros monumentos públicos. Significa la destrucción más completa que puede sufrir un edificio, destrucción de la que no podrá salvarse la menor parcela, destrucción acompañada de una falsa descripción del monumento destruidon (2).

(1) S.P.A. Sobre la restauración del Cuartel del Conde Duque de Madrid, número 71 de la revista C.A.U.

(2) J. Ruskin "Las siete lámparas de la arquitectura», ed. esp. de 1914 (pág. 232). 
Más adelante nos dice "Otra época podría darle otro alman, mas esto sería un nuevo edificio.

"No hablemos pues de restauración, la cosa en sí no es en suma más que un engaño. Podéis hacer el modelo de un edificio como podéis hacer el de un cuerpo, y vuestro modelo encerrará el esqueleto de los viejos muros o el esqueleto de dicho cuerpo; mas yo no veo la ventaja de esto. El viejo edificio está destruido, más aún que si estuviera enterrado en un montón de polvo o sepultado entre una masa de arcilla. Se saca más de las minas de Ninive que de la reconstrucción de Milán. Mas se dirá, la restauración puede llegar a ser una necesidad, de acuerdo. Mirad frente a frente a la necesidad y aceptarla, destruid el edificio, arrojad las piedras a los rincones más apartados y rehacedlos de piedra o mortero a vuestro gusto, mas hacedlos honradamente, no los reemplacéis por una mentira».

Pocas frases pueden resumir tanto en tan poco espacio y pueden ser tan definitorias de la multiplicidad de dudas que asaltan al arquitecto que interviene en un viejo edificio, o programa la rehabilitación en un área definida.

La visión de Viollet Le Duc es por el contrario optimista. Cree en la posibilidad de la restauración y en la posibilidad de la restitución de la forma original a través del estudio concienzudo y sistemático, todo ello a través del buen proyecto de adaptación.

Para Ruskin el tiempo es un factor de embellecimiento que no es posible tocar sin destruir.

En la palabra "Restauración" de su diccionario, Viollet precisa ampliamente los términos válidos de las posibles intervenciones.

Es de interés cuando menciona el nombramiento de $M$. Vitet, en 1830, como inspector general de monumentos históricos y menciona de él las siguientes palabras:

"Reconstruir o más bien restituir en su conjunto o en sus menores detalles una fortaleza de la edad media, reproducir su decoración interior y hasta su amueblamiento, en una palabra, devolver su forma, su color y, me atrevo a decir, su vida primitiva; tal es el proyecto que me ha venido a la cabeza entrando en el Castillo de Concy" (3).

(3) V. Le Duc "Dictionnaire Raisonne de L'Architecture française, tomo VIII, página 19.

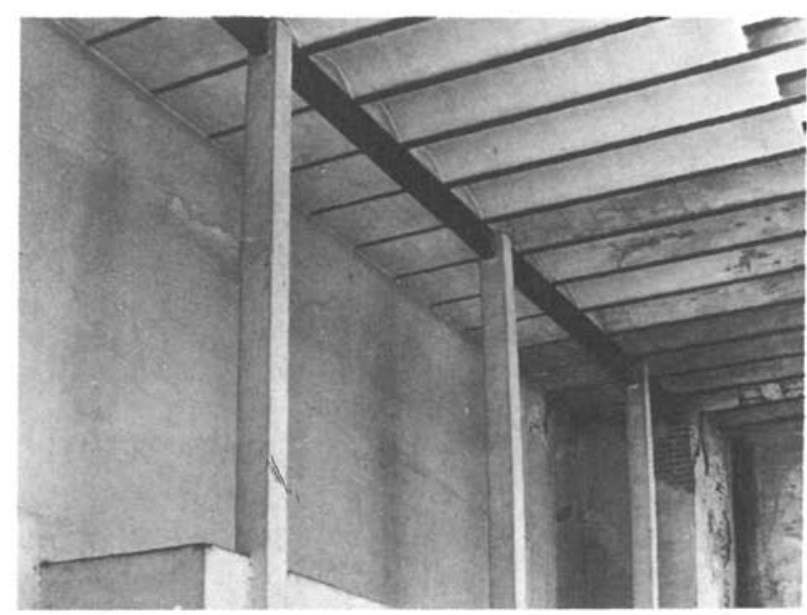

Vista del techo con la estructura metálica aparente. Tanto en pilares, recubiertos de yeso, como en jácenas con bóvedas catalanas la oxidación ha sido acelerada por la humedad hasta niveles de destrucción que han ha sido acelerada por la hume necesaria su sustitución.

Para Viollet restaurar un edificio "no es mantenerle. Repararle o volverle a hacer, es devolverle a un estado completo que incluso pudo no haber existido nuncan.

Más adelante nos dice "por otra parte el mejor modo de conservar un edificio es buscarle un destino y satisfacer perfectamente todas las necesidades que pide este destino, sin hacer cambios en el interior. Es claro por ejemplo que el arquitecto encargado de hacer del hermoso refectorio de San Martín des Champs una biblioteca para la Escuela de artes y oficios debería esforzarse, respetando el edificio y restaurándolo, en organizar las estanterias de modo que no sea necesario cambiar o alterar la disposición de esta sala (4).

Aun mencionando a estos autores, interesados sobre el edificio de valor histórico individual, no he perdido mi idea de concebir las llamadas intervenciones de rehabilitación más dirigidas a salvar un conjunto que un edificio aislado, una estructura urbana que un monumento. A pesar de ello su interés (el del texto), es importante y definitivo.

La rehabilitación de un área determinada se mueve entre dos focos: por un lado el valor que como soporte más económico y conveniente ofrece para la reimplantación de un tejido social, por otro su valor como objetivo arquitectónico transmisor de una cultura y un pasado.

Desde este último punto de vista los problemas de la rehabilitación, dentro de la que se deben incluir las nuevas intervenciones, coinciden en el 

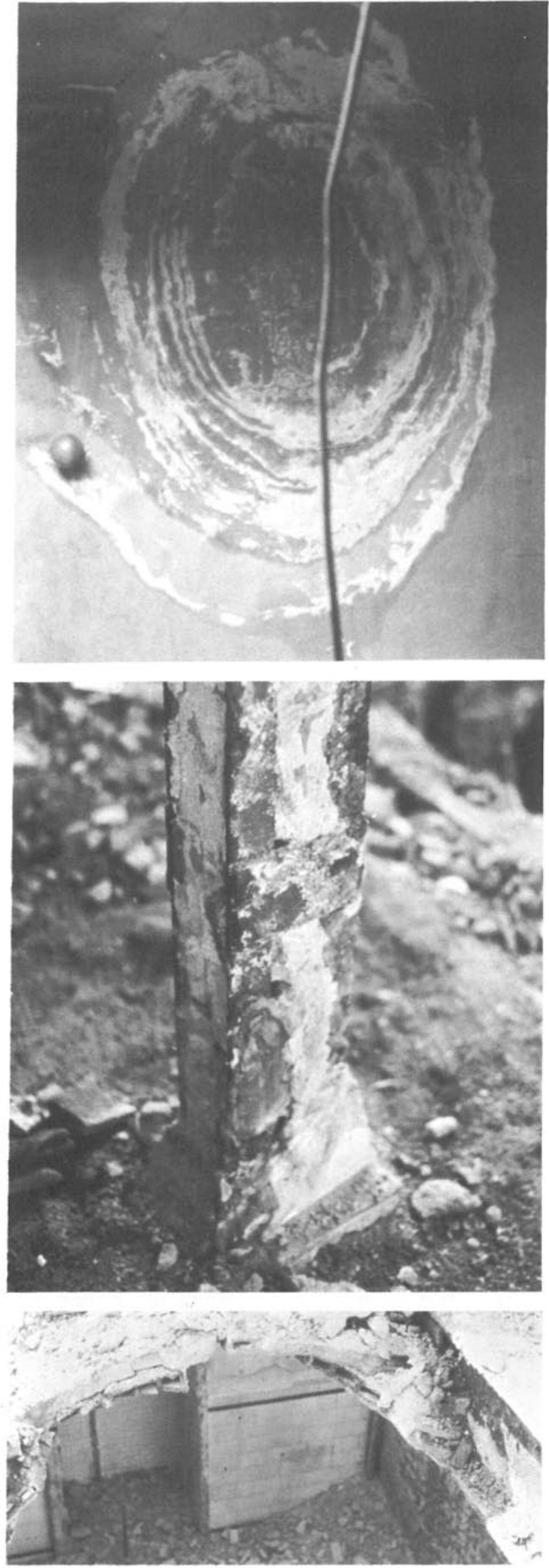

Detalles de la situación actual del soporte a restaurar. fondo con los de la restauración en el sentido en que le preocupaba a Ruskin y a Viollet. El atractivo de un determinado barrio, puede consistir en una imagen histórica, que una rehabilitación optimista puede destruir.

Si nos movemos en términos exclusivamente económicos, el problema se desvirtúa y se reduce al estudio del aprovechamiento de una zona ya dotada de servicios con una posición de privilegio frente a otras áreas.

Un aspecto importante, que no quiero dejar, es el de la necesidad de estudiar áreas homogéneas por su valor social o arquitectónico y el de plantearse las ordenanzas de edificación, de modo que contemplen las intervenciones nuevas a través de volúmenes. En el fondo todo es un problema de fe en la propia arquitectura.

No hay nada más' dramático que las nuevas construcciones implantadas en las proximidades del centro Pompidou, en París, con pretensiones de integración formal, o las numerosas restauraciones que respetando huecos y muros cambian carpintería y materiales hasta hacer irreconocible el antiquo edificio.

No olvidemos, en nuestro país, la obsesión por sacar al exterior las fábricas de ladrillos de los edificios barrocos, ignorando que en general se hicieron para el revoco en el exterior y para el estuco y el yeso en los interiores.

\section{Ayudas financieras}

En lo limitado de este artículo quiero referirme también a las posibles políticas de ayuda económica que podría emprender una administración local, que es a quien puede corresponder la solución de este problema para facilitar la conservación o rehabilitación de los núcleos de interés existentes.

No creo en la posibilidad de conseguir la rehabilitación de un barrio destruido y depreciado sin producir a corto o largo plazo cambios en la estructura social de esta zona. Las políticas llevadas en este aspecto, por algunos ayuntamientos, rozan la utopia o la demagogia.

En general la vivienda será utilizada por personas con un nivel de renta adecuado al valor de cambio de aquélla, y tarde o temprano se producirá el traspaso de unas manos a otras en un mercado libre. 
Las medidas de protección deben pues tender a corregir desequilbios, a permitir que desaparezcan pequentos desalustes, etc.

Tal es el caso de la población anclana residente en núcleos que pueden ser revitalizados. En estos casos puede ser tactible conseguir la permanencia de estas personas, para quienes un cambio significaria un trauma a veces insalvable. pero no se podra garantizar que posterlomente estas vivendas pasen a manos más poderosas.

De igual modo pueden existir determinadas perso nas que por razones culurales se inclinen a perm manecer on una stuacion por encima de su nivel de renia. Sera posible colaborar a allo.

Las nuevas flpologias y su control se presentan sin duda como un arma elicaz para regular el va lor de cambio de las viviendas a traves de su valor de uso.

He iniciado el punto de ayuda financiera hablando de viviendas sin referime a los otros posibles som portes de uso publico.

La lucha contra la lerciarizacion, que tampoco puede ser absoluta, la revitalizacion de los centros en general, solo puede ser corregida a través de la implaniacion de viviendas que satistagan has actuales exigenclas de confort.

Es por esto por 10 que las ayudas económicas deberian dirigirse a este 1 in, y por lo que estas notas inciden especialmente en este sector.

En nuestro caso espanol no podemos olvidar los muchos problemas aconómicos ligados al mante nimiento de las viviendas por parte de los propia tarios individuales o de los caseros, que en la aclualidad no cuentan con ayudas estatales y si de la existencia de una ley de arrendamientos que favorece la destucción planificada de las actuales construcriones.

Los objetivos de los Fondos de Ayuda económ cos deben tender a primar la implantación de nuevas viviendas o la remodelacion $y$ modemizacion de las existentes.

Si las ayudas tinancleras pueden dimirse a los dos tipos de obras posibles - las de restauración y creación de nuevas viviendas - seria preciso diferenciar de lgual modo la función del sistema de propledad y los objetivos propuestos de rehabinlación global, modilicando la estruclura fipologica e incidiendo en la propla estructura del edificio,
- aquellas obras ciestinadas especificamente a me lora de equipo e instalaciones.

Las obras de rehablitacion global deberian aco meterse para el edificio, pero puede permifirse su realizacion por alojamientos individuales.

En este último caso tan sólo se atenderia a los elementos funcionales que la Ley de propledad horizontal permite.

La obtencion de ostag ayudas y la pegulación de las obras facultarán al Ayuntamiento en cuestion para regular la subida te alquler incluso, en su caso, beneficiarse directamente de los mismos a traves de una lasa o cuota especial, para limitar los precios de venta en las primeras transmim siones.

Un apartado importante de las ayudas debe diri girse de igual modo a inanciar obras de consera cion urgente en edificios residenciales.

En este apartado se incluiran aquellas obras sin cuya realizacion el edificio, de cualquier lipo, co menzaria surir daños irreparables en sus elch mentos estructurales iundamentales: cerramientos exteriores, atc., o bien on casos en los que aun sin ser graves desde un punio de visia resistente los daños se pueden considerar como tales por atectar a trabajos o partes interiores del edificio de imposible restiucion, pinturas, estucos, etc.

Este lipo de ayudas deben concederse una vez conocida la capadidad Inanciera de los proplera rios y de los soliciantes aunque, en muchos paim ses, Inglaterra por ajemplo, este aspecto no sea considerado en todos los casos.

Habia que tratar también la proteccion destinada a aquelios edificios o espacios que, en su actual uso, no estén dedicados alojamientos y que tras unas obres de reconversion pueder serto.

En este caso la problemática es más compleja, sobre todo si se trata de obras desthadas a la recuperacion de edificios completos, que deberian ser analkados particularmente y en los que los Ayuntamientos podrian financiar cantidades muy importantes de las obras, imponiendo condiciones de uso y alquiler o controlando la tipologia del proyecto.

Las modalidades dé ayuda económica pueden ir desde el prestamo, aval para conseguiro a las exenciones de too fiscal.

Las modalidades de financiacion deberan ir ligadas a las caracheristicas de cada municipio o zona 
de influencla o a las modalidades de financiacion establecidas en el pais para el acceso a la viyienda.

Por su inferes voy a describir brevemente la situacion en dos paises europeos: Inglaterra y Francia, para presentar al tinal una solución posible a nivel local en un municipio o region en Espana. Debo recordar que estas medidas deberian ir ligadas a olras complementarias como son la revision de le Ley de arrendamientos y la adapiacion de las nor mativas de construcción, tema que desarrollare posteriomente.

\section{Inglaterrata}

En este pais, tanio las autoridades localos como las centrales pueden y dan dinero para distintos lipos de obras en los rocintos catalogados. (Existe un numero elevadisimo de sociedades y funda ciones encargadas de elaborar catalogos, asesorar en las restauraciones o denunciar).

La Secretaria de Estado puede proporcionar Inan ciación a todos los edificlos que ofrecen algún interes arquitectónico, lanto para su mantenimien to como para su reparacion. (Este lipo de prestamos o subvenciones se dirigian a edilcios de imterés artistico nacionaly.

Desde la creación en 1953 del Historic Bullaing Council lorganismo asssor de la Secretana de Eslado) más de 7 millones de libras (unos 1.120 millones de pesetas) han sido utllizados en estos thes, computándose entre 1953 y $1970,6.222$ expedientes de aplicación, unos 366 por año.

De ellos se dieron subvenclones en 1.601 casos y en 1.486 se dedicaron los fondos reparaciones.

La Housing Act de 1969 puso el acento no sólo en la modernización o restauracion sino también en la renovación urbana.

Posteriormente Ia Housing Act de 1974 ha estable cido un mayor control Prente a los propietarios para proteger a los inquilinos de cualquier presión.

La Housing Act de 1969 permitia la financiacion de obras de reparación en viejas viviendas y en las grandes la subdivision en otras más pequenas. Igualmente, viejas casas unifamiliares son dividim das en pisos.

La solicitud de financiación podia hacerse incluso con posterioridad al inicio de las reparaciones, juzgando una comision a través de visitas y estu- dios la certeza y la necesicad de lo realizado o 10 propuesto.

Los propletarios que demendan estas ayudas eco nómicas deben hacer una declaración de sus dis. ponibilldades economicas $y$, en cada caso, se lla por la autoridad competente la ayuda posible.

La condichón para lodo tipo de subvencion as la aportacion por parte del propletario de al menos una canidad igual al dinero recibido. En ningún caso se puede obtener más del $50 \%$ del coste de la obra. En casos excepcionales se puede alcanzar hasta un $90 \%$.

Desde 1971 mas de 1.250.000 edificios han sido rehablltados a raves de subvenclones. Si las autoridades locales entienden que una edilicacion puede ser modernizada, lodos los propletarios u ocupantes pueden beneficiarse de la subvencion.

En caso de venta la subvención debera ser re embolsada anadiendo los intereses compuestos si la venta se realiza antes de 5 anos.

La polltica de intevencion se dirige a dos tipos de zonas:

- Las zonas de reestructuracion urbanistica

- Las zonas de intervención.

En las primeras se fomenta la renovacion, en las segundas, que son zonas degradadas o con una necesidad generalliada, las aulondades locales estan aulorizadas para forar a los propletarios a la renovacion, hasta hacer que nivel de la zona permita su clasificacion como de restructuración urbanistica.

Las zonas de intervención representan del 3 al 4 por 100 del parque edificatorio existente.

Existen tres fipos wundamentalss de subvencion:

a) Discrelionary improvement grants. Concedido por las administraciones locales. En los casos de obras sobre alojamientos existe un limite (en 1971 era de 1.000 libras por cada aloja. mento y en el caso de viviendas unifamiliares de ires plantas convertidas en tres pisos hasta 1.200 libras por pisol. En la actualidad se puede alcanzar hasta 3.200 libras.

Las cantidades son mayores si el odificio tio ne además un interes artístico.

La subvención exige el cumplimiento de 12 especificaciones una vez terminadas las obras: 
1. No deben existir humedades y debe estar en buenas condiciones constructivas.

2. Alcanzar un buen estándar de iluminación y ventilación.

3. Tener una adecuada instalación de fontaneria.

4. Poseer agua caliente.

5. Disponer de W.C.

6. Disponer de bañera o ducha en habitación separada del resto.

7. Disponer de sala de lavado.

8. Disponer de instalaciones de gas y electricidad.

9. Disponer de sistemas de evacuación.

10. Disponer de facilidades para la calefacción.

11. Permitir el almacenamiento, preparación y cocción de comidas.

12. Disponer un depósito de combustible.

Las reparaciones deben hacerse para alcanzar una vida mínima de 30 años.

En el caso de alojamientos las subvenciones son independientes de la capacidad económica del solicitante.

Las autoridades locales pueden también a su vez prestar a razonable interés al propietario su aportación, que debe alcanzar un minimo del $50 \%$ del total estimado por la autoridad local.

Cuarenta y nueve de las cincuenta autoridades locales en materia de alojamiento dan subvenciones para estos temas y reciben ayudas económicas de las autoridades centrales.

b) El Standard Improvement Grants. Dirigido exclusivamente a la mejora de instalaciones y en donde se establece para cada servicio una cantidad determinada con un alcance máximo de hasta 450 libras (en 1971). El uso en el momento de la solicitud debe mantenerse 15 años, aunque no hay limitaciones de venta inmediata.

c) Los "Especial Grants", dirigidos a la mejora de casas con ocupación múltiple sin idea de compartimentarla.
Como datos complementarios hay que decir que en 1971 existian en Inglaterra 17 millones de viviendas de las que 4 eran de más de 80 años y dos no disponian de los minimos servicios higiénicos W.C., baño, etc.

\section{Francia}

Aunque es dificil sintetizar todas las modalidades de Financiación en Francia donde son muchos los organismos encargados de concederlas, es sin embargo posible mencionar los fundamentales.

Los organismos que las conceden son:

- L'agence national pour l'amelioration de l'habitat (A.N.A.H.).

- Las sociedades de crédito inmobiliario.

- Le credit Foncier de France.

- La Caisse des prets dux organismes d'HLM.

- Los organismos colectores del $1 \%$ de las empresas.

- El ministerio del equipamiento.

- El ministerio de agricultura.

- Los Fondes d'amenagement urbain.

- El plan construcción.

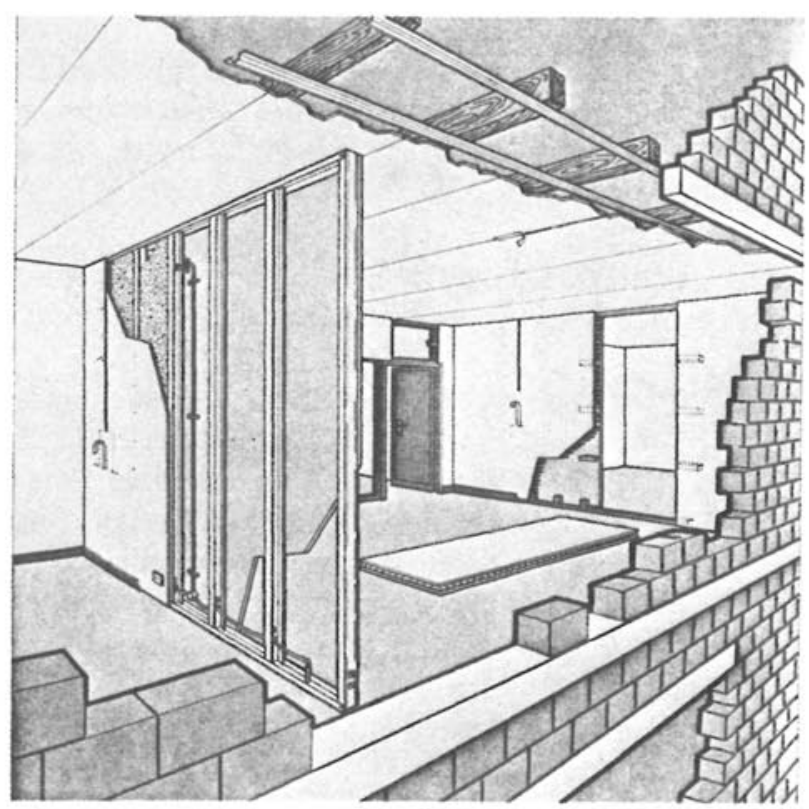

La aparición de semiproductos, unidos a las gamas de componentes existentes, proporcionan una gran facilidad en las obras de remodelación y rehabilitación. 
Los tipos de ayuda se dirigen tanto la rohabillaciôn como a la reconversion con nuevos usos.

Y se pueden establecer dos grandes famllas de casos hacia los que se dirige la inanciacion:

A) Cuando edificio se destra a viviendas.

8) Cuando el edificio se destha a equipamien. 10s.

En el primer caso se pueden dar a su vez va riantes:

a) Cuando el ediniclo ya sara orimamente un edificlo de viviendas.

1) Subvenciones de l'agence Nallonal por lamelioration de thabitat (A.N.A.H.). El A.N.A.H. es un establecimiento público con caracter administrativo creado para estos objetivos. Sus tuentes sag constitum yen por la tasa adiclonal al "droll de bailss.

La financiación se dinge a lo construido antes de 1948

Protegiendo obras de melora y reparaciones.

2) Prestamos de sociedades de crédito inmo biliario, dirigidos a propletarios o a los que quieren acceder a ello.

El limite de las ventes es ol del M.L.M. nás un $20 \%$ en caso de mejora.

3) Ayudas para acceder a la propledad (P.A.P.) destinadas la primera vivienda y en edificlos de mas de 20 ahos de anti. guedad.

Los trabajos de mejora deben representar un $20 \%$ del costo tolal de la operación.

4) Préstamos acordados (P. C.). Estos prés tamos negociados a traves de los Bancos se flian en sus modalidades ante of Estado y las entidades bancarias. Existe una lista oficial de ellas que conceden esta th nanciacion. Las obras deben representar un $20 \%$ del costo total de la operación y conducir una puesta al dia del cumpli miento normativo "Normes minimales dhabilabilite."

5) Presiamos dervados del $1 \%$ de las em presas. $1 \%$ del monto de los salarios dobe deste 1953 ser invertido en alojamiento, 10 que es valido para el aloja miento antiguo.

6) Primas a las meioras del habitat del mim nisterio del equipamiento. El tope es el del M.L.M. más $20 \%$ an el caso de actualizacion nomativa total. En el caso de actualización sólo parcial no se puede alo canzar mas que el $75 \%$ del H.L.M.O.

Esta financiación puede extenderse a 10 construido hasta 1967

b) Cuando el edficio no era originalmente un alojamiento colectivo.

En este caso tenemos:

1) Ayudas al acceso a la propledad. Los trabalos deben representar un $20 \%$ de la operacion y adaptarse la nomativa vi gente.

2) Subvenciones del fondo de equipamiento urbano (F.A.U.) 1976. El F.A.U. Subven ciona a cargo de las autoridades locales:

* Adquisición a restauración.

* Restauración solar.

* Extension del collicio existente.

3) Ayudas del plan constuccion. Programa interministerial desde 1971.

Existe en Francia igualmente una gran cantidad de sistemas u organismos que financian los edifl clos dedicados a equipamiento.

En el caso rancés habría que mencionar las previsiones conomicas de la Ley Marrax de 1962 y las modalidades de intevención.

En las obras de restauracion, las autoridades loca" les montan una compania semipública en la que se abordan estas obras.

Estas companias se ontiende representan a los propietarios y actuan con gran libertad. La financlación as por via estatal y la constituyen subsim dios y préstamos.

Préstamos a medio y largo plazo son concedidas a los propietarios que deben contribuir con hasta un $20 \% 30 \%$ del total.

El plan ha fallado por la insuliciencia de dinero del Estado a las ciradas compantas. 
Les inversiones son de cinco brdenes Iundamentales:

1) Financiacion a traver del Estado:

a) Dirigida a habiat rural, en foma de prin mas acumulables con prestamos bonifica dos medio sérmino por el Crédiro Agricola.

3) Adquisioion - rehabilitacion de alolamien tos $(3.000$ al ano) por el H.L.M.

2) Subvencion A.N.A.H. \&2.000 alojamientos en 1975 unnos 450 millones de trancos).

3) La intevencion de los organismos que reciben el $1 \%$ de las empresas antes mencionedo. Acanzan unos 70 millones de rrancos anuales.

4) Prestamos de las Calas de Ahorro:

a) Prestamos personales al $12.5 \%$ de inte rês. Techo maximo 150.000 rancos amor thades an 20 anos.

5) Ayudas indirectas:

a) Subsidio de alojamiento.

b) Desgravaciones Hiscales a traves de las deducciones sobre gastos en la mejora del aislamiento, restaurachon de estructum ra, intereses sobre préstamos, erw. losta manclacion alcanza tambien a los prople. rarios caseros).

En 974 se uthizaron 8.000 milones de rancos para rabalos de mejora y rehabiliración del parcue inmobliario existente, con Hnanciacion bancaria de orden del $32 \%$ del sotal.

Los infreses exigidos a los préstamos en este pais son sin embargo excesivamente altos, estan do hoy on estudio la posibildad de alcanzar un techo de hasta $200.000 \mathrm{FF}$.

\section{POOLEMAS TEOMCOS COHSTMUTHOS}

Hemos hecho reterencia anteriomente los problemas derivados de la aplicacion de las actua les nommativas en la obras de rehabmitacion o restauracion.

Esta siruacion esta molor resuela en paises como inglatera, en los que existe una antigua tradichón restauradora y unas excelentes regulaciones cons. tructivas.
En ruestro nais nos encontramos trente incon vententes diversos. Por un lado la nomativa y por otro la valra de radicion que presenta como dudosa cualpuler obra no reanzada de nusvo en su sotalload.

A Estos hay que anadr la falla de oficlos y ténn cos especializados que permitan realizar astas obras con al menor dafo posible lo existente

Sl las nomativas europeas son herederas de los planteamientos higienistas del XIX, en el caso es. parol muestra nommativa reflaja ademas el pasado reclente, en ol que la especulacion y ol mercado de demanda existente permisic vender todo lo construido.

Por ello está texida tambien de un are policial y descontado vue poco ayuda a la buena realiza cion de construcciones y arquitectura.

Frente una nomaiva exigenclal como la exis lente en Indaterra, nosolros debemos aceptar en general unas normas techicas llas y en muchos casos sobrecargadas para compensar ol asperado incumplimiento.

No hablemos de la nomatva urbanistica, más propla para regular el reparto squibrado de un botn, que para corregir una arquinccura razo nable.

Es evidente que las antiguas construcciones no satistacen nuestras actuales exigenclas estumbu rales, por ello es presiso en este y en otros terre nos contemplar a hivel normetivo la nectsidad de respetar on muchos casos los sistemas ya exis tentes por razones de economia y comeniencia estructural.

S se adapta un edficio para un uso de vivendas, es preciso contar con la posibllided de conservar anmuos hriados con viguala de madera que pueden proporcionar las prestaclones requeridas sin recurrir - aspecto en muches ocasiones no acon selable-, a su sustucion por otros de mas peso, de tipo metálico o de homigón armado.

No se deben owidar los capivulos de la nomativa que atienden a la luminacion, o la ventilación, por otra parte absurdos. Las antiguas viviendas no cumplen con los descos expresados por oropius, pero ello no las hace menos arractivas.

Desde un punto de vista economico las dudas son tambien frecuentes, por la valta de radicion apun lada, pero también por la ausencia de estudios serias cue hayan avaluado las dibrencias de caste 
Id

\begin{tabular}{|c|c|c|c|c|c|c|}
\hline $\begin{array}{c}\text { FPO DE OBRA } \\
\text { Y } 150\end{array}$ & SOLYCTEAME & CLASE DE AYUDA & CUAMRA & 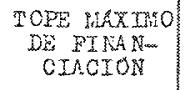 & CARTTULOS RERIDIDOS & $\mathscr{D E L} F_{0} A_{0}$ \\
\hline 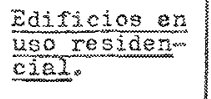 & & & & & & \multirow{3}{*}{$\begin{array}{l}30 \% \text { de } 20 \text { d. } \\
\text { ponible con } \\
\text { preferencia a } \\
\text { ia rehebilitg } \\
\text { cibnglobal. }\end{array}$} \\
\hline $\begin{array}{l}\text { A) Rerabili- } \\
\text { tacion gla- } \\
\text { bal del edi- } \\
\text { ficio. }\end{array}$ & EI propiotexia & $\begin{array}{l}\text { Pxésteno de } 10 \text { a } \\
20 \text { años nás posi } \\
\text { ble ayuda a pos } \\
\text { intereses del } \\
\text { resto. }\end{array}$ & $\begin{array}{c}50 \% \text { del } \\
\text { total }\end{array}$ & $600.000 / A 1$. & Todos. & \\
\hline 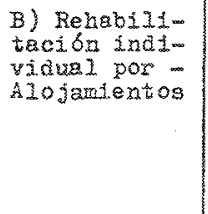 & $\begin{array}{l}\text { Exopletario } \\
\text { Inguiltno }\end{array}$ & 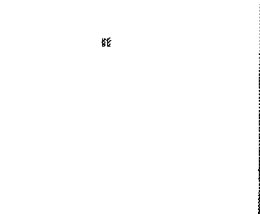 & $"$ & $500.000 / A 2$. & 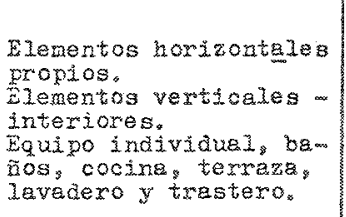 & \\
\hline $\begin{array}{l}\text { C) We jores - } \\
\text { de estandard }\end{array}$ & & & & & & \multirow{3}{*}{$\begin{array}{l}20 \% \text { de } 10 \text { ais } \\
\text { ponible con } \\
\text { preferencia } \\
\text { la we jork gle } \\
\text { bal. }\end{array}$} \\
\hline 0,1$)$ Gabal. & Propteterio & $\begin{array}{l}\text { Préstamo on } 10 \delta \\
20 \text { años. }\end{array}$ & $\approx$ & $250.000 / \mathrm{A} 1$ & 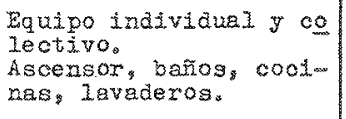 & \\
\hline$c_{\text {2) Por } 210}$ & $\begin{array}{l}\text { Eropietexio } \\
\text { Inquilino }\end{array}$ & 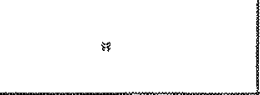 & : & $200,000 / \mathrm{kI}$ & $\begin{array}{l}\text { Equipo Individuei. } \\
\text { Baños, cocina y lays- } \\
\text { daro. }\end{array}$ & \\
\hline 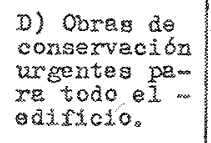 & Propletario & $\begin{array}{l}\text { Próstano de } 10 \text { a } \\
20 \text { años }\end{array}$ & $100 \%$ & $380,000 / \mathrm{AL}$. & $\begin{array}{l}\text { Cimentaciones y es- } \\
\text { tructura, cubsertag } \\
\text { cexreanientos y eva- } \\
\text { ocacion (l) }\end{array}$ & $\begin{array}{l}15 \% \text { de } 20 \text { dusmo } \\
\text { pondinde. }\end{array}$ \\
\hline 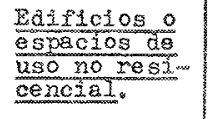 & & & & & & \multirow{3}{*}{$\begin{array}{l}25 \% \text { del dispo } \\
\text { ryblo con pre } \\
\text { ferencia a } \\
\text { reconversion } \\
\text { globes. }\end{array}$} \\
\hline 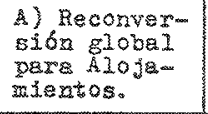 & Proplatario & $"$ & $50 \%$ & $700.000 / \mathrm{Az}$ & Trodos. & \\
\hline $\begin{array}{l}\text { 8) Reconver } \\
\text { sion parcial } \\
\text { pera hlojam } \\
\text { satentos }\end{array}$ & Propietario & * & $50 \%$ & $600,000 / \mathrm{Al}$. & 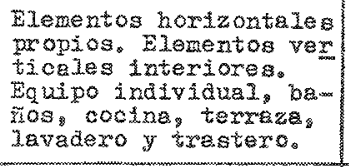 & \\
\hline 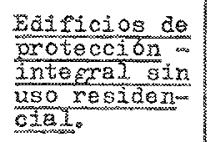 & Propletaxio & F & $50 \%$ & $5.000 / \mathrm{ma}^{2}$ & 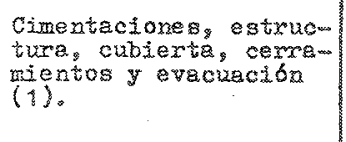 & 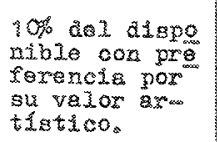 \\
\hline
\end{tabular}

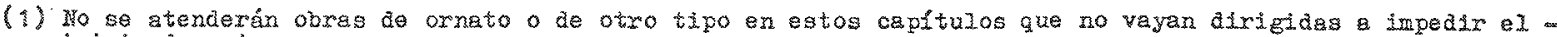
intiso de rusing ow

En este cuadro se apuntan posibles tipos de ayuda financiera en razón del: soliciante, sipo de obra, etc. No hay que olvidar que su planteamiento esta on razón de la situación de urgencia que este problema reviste en nuestro pais. (El presente cuadro fue elaborado por el autor en enero de 1982 )

entre consevar o reconstruir, o simplemente que sean conocidos los limites porcentuales de las in tervanciones optimas.

En el caso de Madrid ol problema y las contra dicciones son palpables. Hasta nuestros dias se ha aplicado una polltica, por parte de los propic tarios, dirigida a la sustivucion completa del edifi cio, provocando la ruina acelerada.

Hoy, en cambio, las disposiciones del Ayunta mienio y de Bellas Artes hacen imposible la do claracion de ruina de muchos edificios que en rea lidad 10 están.

Junto a esta situacion nos encontramos con el desconocimiento real de lo que signilica en muchos casos conservar, reconstruir o derrbar. El Plan Especial de Proteccion de adificios y conjun los de interés hoy en vigor en esta ciudad, tiene en su contra la ausencia de un fondo de ayuda $y$ la pobreza constructiva do muchas de nuestras construcciones.

No es 10 mismo trabajar sobre muros de carga de ladrillo, de dos o rres plantas de alura, que ha" 
cerio sobre centenarios sistemas de entramado de madera con relleno de yesones y cascote que por pudrición de la madera se han converfido en auténticos elementos de carga a lo que colabora la misma tablquería.

En cualquier caso lo que es preciso conocer y experimentar son cuadros de opciones, estudios tipológicos que permitan adecuar los nuevos usos o programas a las antiguas estructuras.

Sera preciso para ello conocer lo que significa cada intevención y poner a punto un sistema de evaluación rápida que permita predimensionar costos en virud de experiencias parecidas siempre que estas existan.

Desde el punto de vista puramente constructivo hablar de técnicas de rehabilitación pasaria por un rratado previo de patologia constructiva.

Como decia Ruskin ualgunas holas de plomo colo. cadas a liempo oportuno sobre el techo, el desbrozamiento oportuno de la hojarasca y de las ra. mitas obstruidoras de un conducto, salvaran de la ruina los techos y muebles a la vezm. De este modo ponia de manifiesto el mal mayor que suele aquejar a las consirucciones, la perdida de resis. tencia frente al agua exterior y la rotura de los conductores internos.

La mayor parte de los problemas de consenación de los edificios se derivan de las pudriciones de elementos estructurales, 0 de los asientos por vias de agua no controladas. Entre estas causas no son despreciables los problemas de descompo sición de la piedra por humedad caplar o disolum cion quimica.
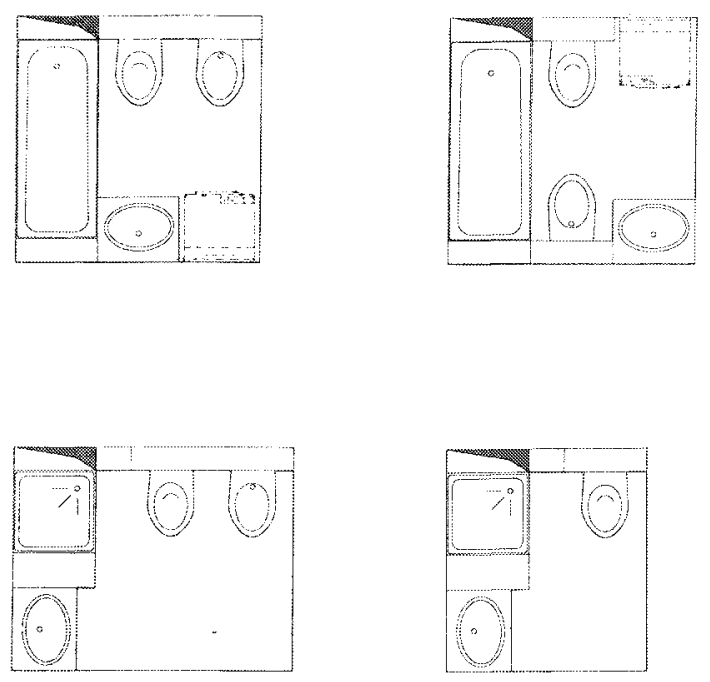
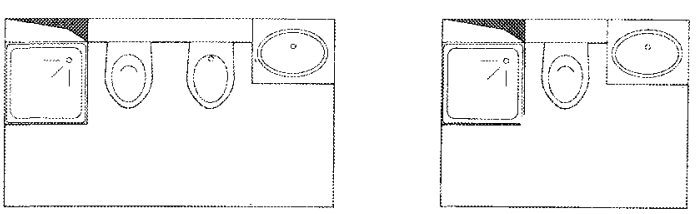

En Madrid ha sido técnica habitual de muchos propietarios el dejar las ventanas de edilicios ya vacios abiertas, o bien no reparar las averias an la pudricion y ambien el hundimiento progresivo de los cimientos.

De este modo las intervenciones posibles en ol actual parque madrilefo contarán en muchos ca. sos con estos problemas: necesidad de sanea. miento de estructura y cimientos $y$, por supuesto, de toda la red de suministro y evacuación.

En cualquier caso dependerá el thpo de obra del tipo de intervención prevista. Si se piensa en la definicion de "Soporte" que hace Habraken se in dividualizara en muchos casos un esqueleto estructural y se mantendra el cerramiento, cajas de escalera o patios (en función lambien del nivel de protección exigido), incorporando en el interior nuevos conductos y nuevos tabiques en funcion del programa.

Esto no será siempre posible, puesto que estos edificios requeriran, para poder seguir proporcio nando las mismas prestaciones que cuando estam ban en buen estado, contar con los elementos do compartimentacion antes existentes.

La liberación de plantas, puede en muchos casos, presentar graves consecuencias estructurales y por supuesto arquitectónicas.

De los viejos soportes es posible aprovechar su inercla férmica, sus cualldades de aislamiento acústico y sus mas holgadas proporciones arquitectónicas. Habrá que incorporar también un me Jor aislamiento témico, en base a doblados de
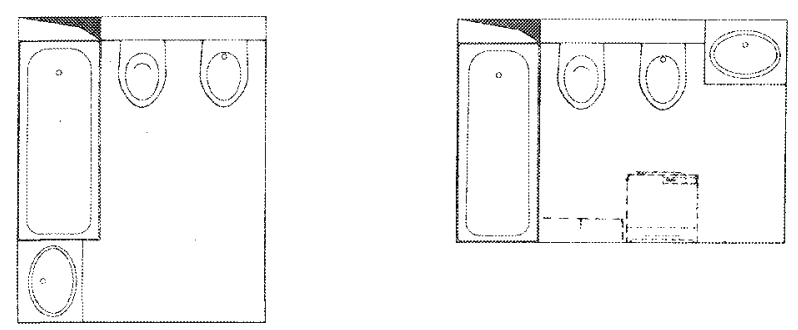

Tipologia de bloques técnicos de la casa Zanussi. 
tabiquería y restauración de las carpinterias, sellando o incorporando doble cristal y nuevas instalaciones. Este problema puede resolverse racionalizando al máximo la nueva distribución (en el caso que se pretenda), o introduciendo bloques técnicos de baño y cocina de carácter ligero, de modo que permitan reducir al minimo el número de conductos y perforaciones nuevas necesarias.

Lógicamente los problemas difieren en función del tipo y de la fecha de construción, asi como de su estado de conservación.

Nos referiamos antes a las construcciones de entramados del XVIII y XIX e incluso más antiguos que se encuentran en Madrid. En general estos edificios sufren problemas de asiento, de deformaciones permanentes de elementos estructurales o de excesivas flechas en los forjados. Las estructuras de madera sufren particularmente, por efecto de los hongos como el Merulius Lacrimans, de grandes efectos destructores en aquellos sitios en los que la ventilación es deficiente; igualmente en orden de importancia hay que mencionar la coniophora cerebella y el Lenzites obetina.

El efecto de estos hongos es siempre la destrucción de la lignina o de la celulosa, pero respetan-

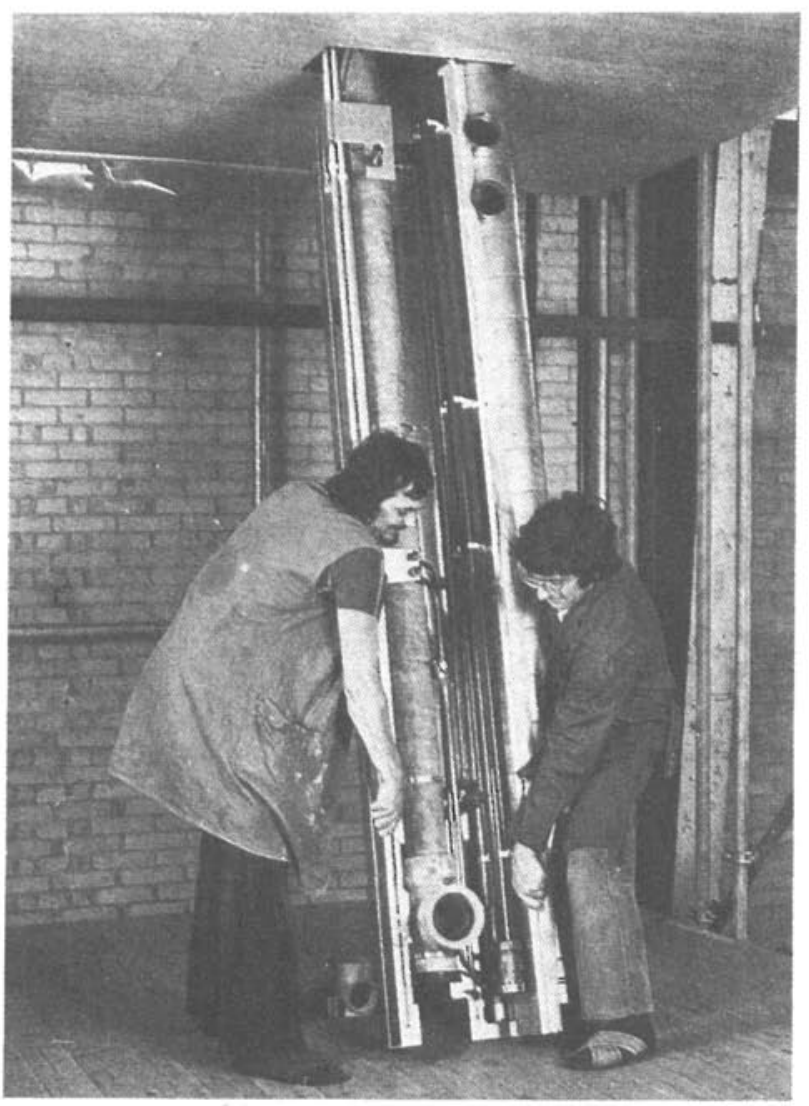

El bloque técnico es quizás el componente más desarrollado que puede cumplir un papel racionalizador más claro en las obras de rehabilitación. do la estructura externa; sus consecuencias estáticas son evidentes.

Los insectos como las termitas o diferentes coleópteros pueden producir iguales resultados, en algunos casos no aparentes desde el exterior.

Cuando estos problemas afectan a los elementos de cubiertas, con frecuencia se puede recurrir por su importancia a la sustitución de los elementos deteriorados o al saneamiento completo de la cubierta, Viollet ya se referia a la posibilidad de sustituir los elementos triangulados de madera por cerchas metálicas. Este problema ha sido uno de los más clásicos de las restauraciones, o simples reparaciones, en arquitectura y fue causa y origen de la aplicación de las bóvedas tabicadas en el siglo XVIII por Conde D'espie en Tolosa. Hoy en los forjados se recurre también al doblado de la estructura de madera por viguetas metálicas.

Un problema constructivo clásico de aquellas intervenciones, en las que se cambia el programa, es la necesidad de abrir nuevos huecos. He presenciado esta operación incluso en edificios prefabricados, en base a paneles pesados portantes con las dificultades que la eliminación de un panel de éstos implica. Las posibilidades de producir asientos son evidentes, no sólo por la misma operación de apeo, sino por la evidente transformación del flujo de cargas en la cimentación.

En función de los espesores y características de los muros, sobre los que se deben practicar los huecos, son las técnicas para hacerlos. Los morteros a base de resina epoxi pueden cumplir en este tipo de obras un importante papel.

Por último un tema importante que me gustaria iniciar es el de los acabados de fachada. Enfoscados, revocos y pinturas constituyen a la hora de terminar las obras uno de los mayores problemas técnicos y estéticos. En parte por la desaparición de viejos oficios que pueden trasmitir lo antiguo, también por la presencia de nuevos productos que si bien ofrecen un gran número de prestaciones, proporcionan un cambio de aspecto tan notable que puede no ser aconsejable. Es interesante recordar las antiguas técnicas de estucado a la cal o, a fuego, hoy casi imposibles de reproducir, y que fueron técnicas en uso hasta hace pocos años.

En general estos acabados están sujetos a las duras condiciones atmosféricas, especialmente en la parte superior de los edificios sufren también de las diferentes presiones de humedad entre el exterior y el interior, y están sujetos a fuertes tempe- 


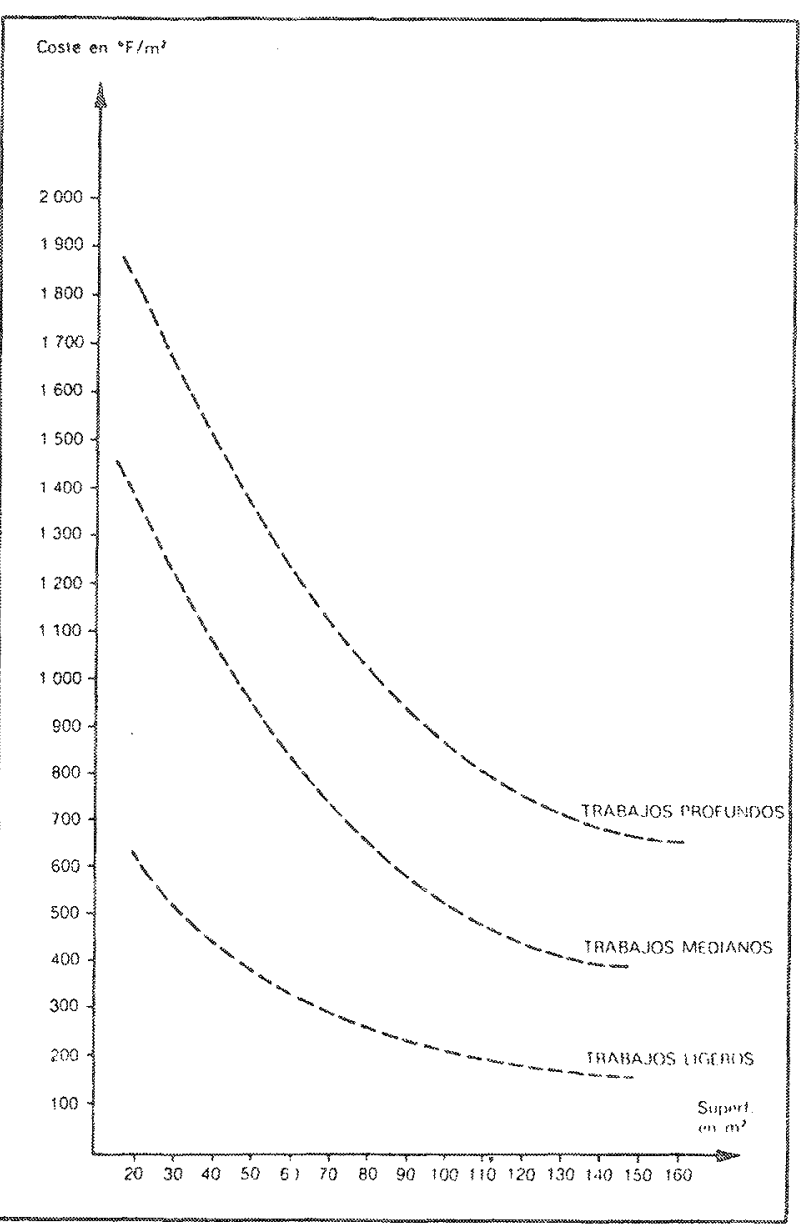

Esta estadistica realizada sobre más de 600 viviendas en Francia, muestra la importancia porcentual del equipo a instalaciones en los apartamentos de pocos metros y cómo sobre los $100 \mathrm{~m}^{2}$ (se deben entender útiles) se alcanza una cota minima aceptable de repercusión.

IDel libro del Ministère de IEquipement, Direction de la construction.

raturas en los conducios. Antiguamente se tra bajaba con cales apagadas que conservaban sus caracteristicas plásticas más fiempo.

En general, los entoscados se aplicaban una vez que el muro estaba muy seco para evitar aprisio nar agua en su interior. Despues se sustituyeron estas cales, lanto las apagadas como las aereas, por cales hidraulicas arificiales que fraguan más rápidamente; estos entoscados hidráulicos, a los que se les contiaba un comportamiento impermea ble, ham sido sustituidos también por morteros de cemento, puro o mezclado con cal, lo que produce irremediablemente graves problemas de fisuraciones y por tanto de problemas capilares que pueden agravarse por ef pequeno espesor de los muros.

Los defectos que pueden acusar estos acabados son de varios tipos:

a) Una estructura de soporte debil, que permile el desprendimiento del material dejando las rábricas al alre.

b) Un soporte poco poroso, ladrillos poco adhe rentes que pueden igualmente permirir la caida del revestimiento.

c) Lesiones debidas a movimientos estructurales.

d) Agua retenida entre el esfoscado y el muro.

e) Fenomenos de heladicidad que pueden helar el agua contenida on lisuras y bolsas.

1) Ataques quimicos debidos a sales existentes en las fabricas o a el $\mathrm{CO}_{2}$ y a anhidrido sulfuroso del aire en la cludad.

La aparición de materiales de revestimiento plástico y su aplicación en lugar de los clásicos acabados puede causar serios problemas si no se cono

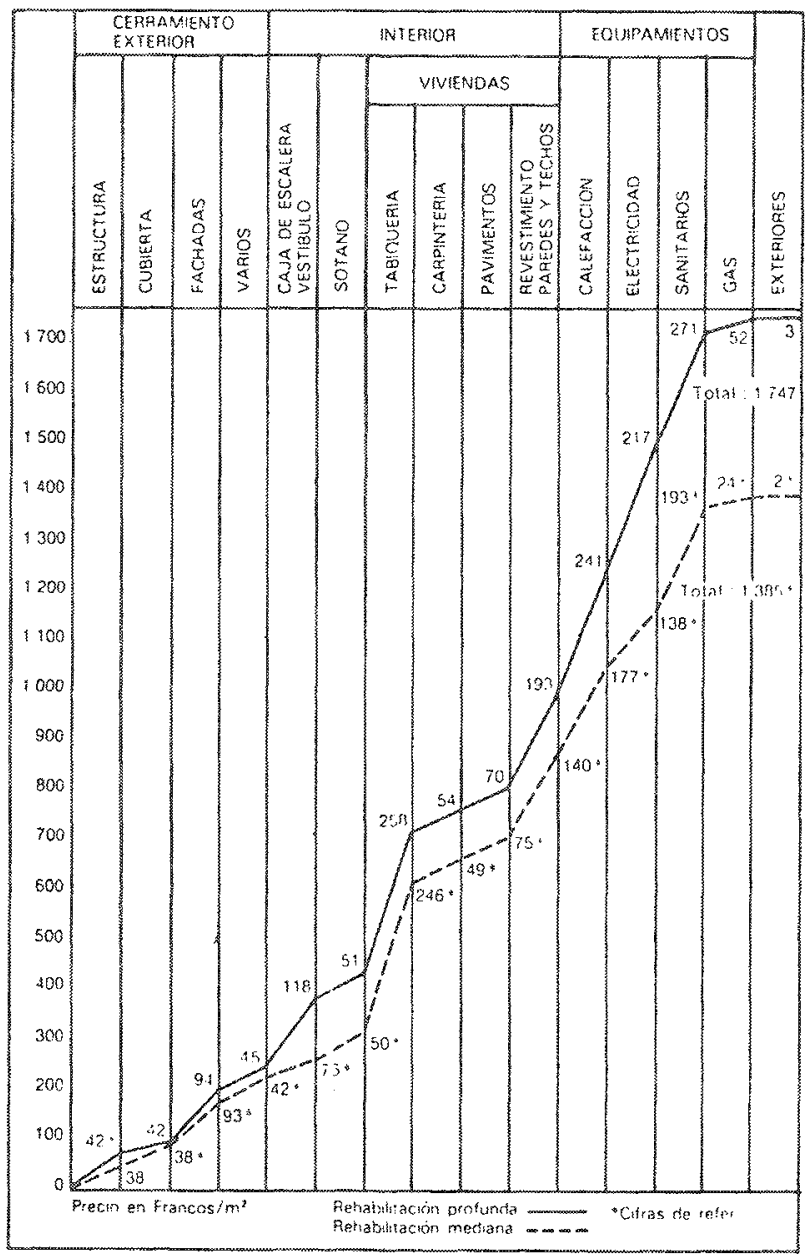

Comparacion de la descomposicion de los precios enke tas dos soluciones.

Este grásico obtenido de la edición española de Gustavo Gill "Renabill. tación de la vivienday acusa la repercusión porcentual por capitulos de obra: desgraciadamente no coincide totalmente con los téminos de A.R.C., no diferencia entre evacuación y suministro, pero sirve para nuestros fines. 
ce, en profundidad, el equilibrio interior-exterior del muro.

En efecto, la mayor impermeabilidad de estos productos puede ser negativa. Los antiguos acabados, en base entoscado de cal o cemento y revo cos, ofrecian una porosidad decreciente del exterior al interior; cubrir estas capas con una nueva impermeabilización produce embolsamientos aplos para sufrir problemas de heladicidad.

Las clásicas pinturas de dispersión, con las que en los años cincuenta y sesenta se terminaban muchos de los edificios restaurados, han demostrado igualmente su mal comportamiento.

Estas pinturas están constituidas en general por dispersiones en agua de resinas sintéticas, gene ralmente acetatos o copolimeros de polivinilo. Los emulsionantes que llevan estas mezclas son altamente hidróllos y absorben agua en grandes cantidades reteniendola durante largo tiempo.

Estas peliculas externas, saluradas de agua, impiden la difusion del vapor desde el interior del edi. liclo, havoreciendo la formación de condensaciones.

Estas condensaciones que arrastran sales del muro producen por saporificación el desprendi- miento de partes de la pintura haciendo muy difi. cil o casi imposible, su reparación.

Son las resinas de silicona, las que en paramentos de piedra o de ladrillo visto, ofrecen una me jor solución.

En general hay que pensar que, en aquellos edifi clos en los que no existía cámara de are, la labor de doblado puede realizarse preparando cámaras de aire de modo que sea factible la introducción de venulación o de barreras de vapor adecuadas.

Para lerminar estas notas, sobre pinturas extemas en rachada, debemos recordar aquello que es pre ciso conocer: su resistencia a la saponificación, su resistencia los agentes atmostericos, su re sistencia a la fisuracion y su permeabllidad al vapor.

La relación que mide la concentración de pigmentos en volumen C.P.U. es importante y viene dada por la Sormula:

CPV $\%=\frac{\text { Volumen de pigmentos }}{\text { Volumen de pigmentas }+ \text { volumen de conglomerantes }} \cdot 100$

Es recomendable para esta relación un valor com prendido entre el 50 y el $55 \%$.

\section{publicación del I.E.T.C.C.}

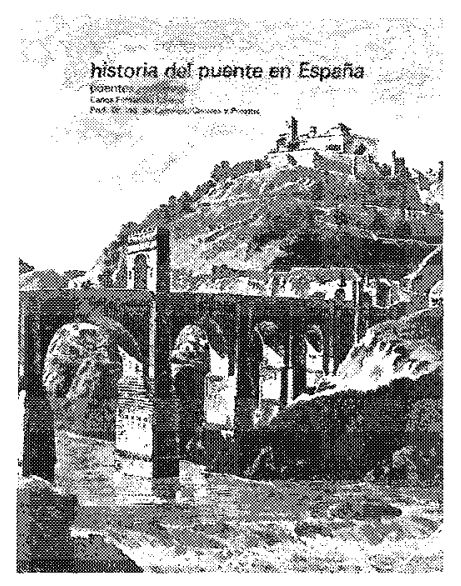

historia del puente en España

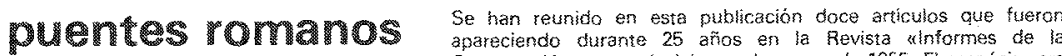
Construcción, a partir del mes de marzo de 1955. El propósito esa mucho más ambicioso pues se trataba de hacer una xhistoria del puente eri España), pero hasta el momento actual solo se ha revisado la época romana, si bien el autor tiene la interición de prolongar la historia hasta cuando sus años de vida le den lugar.

Prof, Dr.ing. de Caminos,

Canales y Puertos

Unos apendices añadidos a los doce articulos originales intorman sobre las variaciones experimentadas por algunos puentes más importantes camo la del traslado de las ruinas meior conservadas del puente de Alconétar,

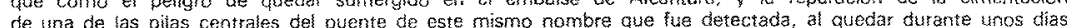
cortado e curso de Taio, para reatizar al montaie de tos desagïas de fondo correspondientes a la presa del citado cortado e

Un volumen encuademado en cuché, a dos colores, de $21 \times 27,5 \mathrm{~cm}$, compuesto de 554 páginas, 105 grabados, 年 dibujos, 753 fotos blanco y negro, 24 fotos color y 910 dibujos de tinea.

Madrid, rag1.

Precios: España, 3.000 ptas.; extranjero, 43 \$ USA. 